\title{
Assessment of antioxidant activity of citronellal extract and fractions of essential oils of Citrus hystrix DC
}

\author{
Warsito Warsito $^{1 \star}$, Noorhamdani Noorhamdani ${ }^{2}$, Sukardi Sukardi ${ }^{3}$, Suratmo \\ Suratmo ${ }^{1}$ \\ ${ }^{1}$ Institute of Essential Oils, Faculty of Mathematic \& Natural Sciences, Brawijaya University, ${ }^{2}$ Laboratory of Microbiology, \\ Faculty of Medicine, ${ }^{3}$ Department of Agroindustrial Technology, Faculty of Agriculture Technology, Brawijaya University Jl. \\ Veteran, Malang, East Java, Indonesia
}

${ }^{*}$ For correspondence: Email: warsitoub88@yahoo.com

Sent for review: 13 February 2017

Revised accepted: 15 May 2018

\begin{abstract}
Purpose: To evaluate the antioxidant activities and chemical compositions of citronellal extract and fractions of essential oils of Citrus hystrix.

Methods: Antioxidant activity was examined using 1,1-diphenyl-2-picrylhydrazyl (DPPH) assay. Essential oil was produced by steam distillation while isolated citronellal and fractional distillates were obtained on a PiloDist 104-VTU fractional column at $5 \mathrm{mBar}$ pressure and a reflux ratio of 20:10. Gas chromatography-mass spectrometry was used to determine their chemical composition.

Results: All the essential oils produced from parts of $C$. hystrix, i.e., twigs oil (CHT), leaves-twigs oil (CHTL), leaves oil (CHL), and fruit peels oil (CHP), citronellal extract of CHL oil (CHLCE) and the distillation fractions of $\mathrm{CHT}$ oil (F1-F9), exhibited antioxidant activity. CHP exhibited the highest antioxidant activity. The chemical composition of CHT, CHTL and CHL was dominated by oxygenated monoterpenes (OMs), whereas that of CHP and F1 comprised mainly of a hydrocarbon monoterpene (HM).

Conclusion: The antioxidant activities of essential oils from parts of $C$. hystrix and the fractions produced by essential oil fractional distillation exhibited a combination of HMs and OMs. Essential oils of CHP and F3 produced from the essential oil fractional distillation of CHT with a nearly equal composition of HM and OM compounds had higher antioxidant activity than the other essential oils and fractions, with $I C_{50}$ values of 6.43 and $2.40 \mu \mathrm{L} / \mathrm{mL}$, respectively.
\end{abstract}

Keywords: Citrus hystrix, Essential oil, Hydrocarbon monoterpene, Oxygenated monoterpene, Antioxidant

\footnotetext{
This is an Open Access article that uses a funding model which does not charge readers or their institutions for access and distributed under the terms of the Creative Commons Attribution License (http://creativecommons.org/licenses/by/4.0) and the Budapest Open Access Initiative (http://www.budapestopenaccessinitiative.org/read), which permit unrestricted use, distribution, and reproduction in any medium, provided the original work is properly credited.

Tropical Journal of Pharmaceutical Research is indexed by Science Citation Index (SciSearch), Scopus, International Pharmaceutical Abstract, Chemical Abstracts, Embase, Index Copernicus, EBSCO, African Index Medicus, JournalSeek, Journal Citation Reports/Science Edition, Directory of Open Access Journals (DOAJ), African Journal Online, Bioline International, Open-J-Gate and Pharmacy Abstracts
}

\section{INTRODUCTION}

Herbs and essential oils (EOs) are sources of bioactive compounds. These ingredients have been used for medicinal purposes and also used as the source of new drugs $[1,2]$. The high content of phenolics and flavonoids in medicinal plants has associated with their antioxidant activities, which involve in the prevention of agerelated disease, particularly those caused by oxidative stress [3]. According to previous studies, EOs exert biological activity to treat 
infectious and cardiovascular diseases and against pathogenic bacteria [3,4]. EOs are also widely used as food preservatives, cosmetics, virucides, fungicides, antiparasitic, and insecticides, as well as anticancer, antioxidant, and antidiabetic agents $[1,2]$.

EOs are volatile and are composed of complex compounds. As the secondary metabolites of aromatic plants, they can identify by their strong odor. These volatile molecules include monoterpenes (hydrocarbon monoterpenes [HMs] and oxygenated monoterpenes [OMs]) as terpenes biogenerated by the mevalonate pathway and sesquiterpenes (hydrocarbon sesquiterpenes and oxygenated sesquiterpenes). They also contain phenolic compounds, which are derived via the shikimate pathway [4]. Biosynthesis process diversity in different parts of the plant leads to different metabolite compositions. Therefore, the EO content in different parts of the plant varies, including the roots, stems, leaves, flowers, fruits, and seeds [5].

Previous researchers have noted that some EOs from the Malaysian citrus (Rustacea), including Citrus aurantifolia, C. grandis, C. hystrix, and C. microcarpa, have different chemical compositions and bioactivities, including antimicrobial and antifeedant activities [6]. The distribution of major and minor components of each kaffir lime oil fraction can be obtained using fractional distillation [7]. Furthermore, the use of different cooking methods causes various effects on the phenolic compounds and antioxidant properties of kaffir lime leaf [8]. This study aimed to test the antioxidant activity of EOs from parts of $C$. hystrix and citronellal extract and to identify changes in their antioxidant activity and chemical composition by fractional distillation.

\section{EXPERIMENTAL}

\section{Plant material}

The plant used in this study was $C$. hystrix. According to Backer and Van den Brink (1968), it is in the family Rutacea, the genus Citrus, and the species $C$. hystrix DC. C. hystrix twigs and $C$. hystrix twigs-leaves $\left(\mathrm{nD}^{20} 1.44 \mathrm{~g} / \mathrm{m}\right.$ and specific gravity of $0.85 \mathrm{~g} / \mathrm{mL}$ ) obtained from a local farmer in Ngunut, Tulungagung, Indonesia in April 2015. Oils from $C$. hystrix leaves and peels collected from steam distillation of leaves and peel were collected from $C$. hystrix plants grown in Ngunut, Indonesia in May 2015. Samples were stored at the Institute of Essential Oils, Brawijaya University.
Distillation of C. hystrix oil from leaves and peels

Fresh C. hystrix leaves $(2 \mathrm{~kg})$ and peels $(2.7 \mathrm{~kg})$ were separately distilled with water-steam for four h. EOs were dried over anhydrous sodium sulfate and stored at $4^{\circ} \mathrm{C}$ for further analysis.

\section{Fractional distillation of $C$. hystrix leaves and twigs oil}

C. hystrix twigs oil $(2 \mathrm{~L})$ distilled by steam distillation under reduced pressure using a PiloDist 104-VTU column with a column length of $2 \mathrm{~m}$ and 120 stages equipped with a heating jacket coat as the heat source. Fractional distillation was performed using a 20:10 reflux ratio and five mbar of pressure. Each fraction collected, and the volume was measured. The distillation process conducted at the LIPI Research Center for Chemistry, Serpong, Indonesia.

\section{Citronellal extraction of $\boldsymbol{C}$. hystrix leaves oil}

Citronellal of $C$. hystrix leaves oil was isolated by adding $20 \mathrm{~mL}$ of twigs-leaves oil into $15 \mathrm{~mL}$ of saturated $\mathrm{Na}_{2} \mathrm{SO}_{3}$ while being stirred homogeneously. The $\mathrm{pH}$ adjusted to $\sim 8$ with the addition of $1 \quad \mathrm{M}_{2} \mathrm{H}_{2} \mathrm{SO}_{4}$ drop-wise. The precipitation salt was filtered and washed with ethanol. The salt was then hydrolyzed using saturated $\mathrm{Na}_{2} \mathrm{CO}_{3}$ solution $(1.424 \mathrm{~g} / 4.07 \mathrm{~mL}$ in distilled water), and the organic layer was separated. The organic phase (citronellal) was collected in vials, dried under anhydrous sodium sulfate, and stored at $4{ }^{\circ} \mathrm{C}$.

\section{Evaluation of antioxidant activity}

Antioxidant activities of the EOs were evaluated by measuring DPPH bleaching (purple-colored ethanol solution). All samples were prepared at various concentrations $(1.25,2.5,5,7.5,10$, $12.5,15$, and $20 \mu \mathrm{g} / \mathrm{mL}$ ) in ethanol solvent; $1 \mathrm{~mL}$ of $0.4 \mathrm{mg} / \mathrm{mL}$ DPPH solution (in ethanol) was added to the samples. The solution was mixed using a vortex and incubated for $30 \mathrm{~min}$ at room temperature in the dark. The absorbance was measured at $\lambda=517 \mathrm{~nm}$. Butylated hydroxytoluene (BHT; Sigma-Aldrich, St. Louis, MO, USA) used as a positive control. The inhibition percentage of free DPPH radicals (I \%) was calculated using Eq. (1):

$I(\%)=\{1-(\mathrm{As} / \mathrm{Ab})\} 100$

where $A b$ and $A s$ represent the absorbance of the blank and sample reaction, respectively. 


\section{Gas chromatography-mass spectrometry (GC-MS) analysis}

GC-MS analysis performed using a Shimadzu QP 2010S equipped with a DB-1 capillary column (L $30 \mathrm{~m}$, ID $0.25 \mathrm{~mm}$ ). For GC-MS detection, an electron bombardment system was used with ionization energy of $70 \mathrm{eV}$ (injector temperature, $300^{\circ} \mathrm{C}$; detector temperature, $320^{\circ} \mathrm{C}$; pressure, $12 \mathrm{~Pa}$ ). The column temperature was initially set at $50^{\circ} \mathrm{C}$ and gradually increased to $260^{\circ} \mathrm{C}$ at a rate of $5^{\circ} \mathrm{C} / \mathrm{min}$. Helium was used as the carrier-gas at three $\mathrm{mL} / \mathrm{min}$ flow rate. The components were identified based on the comparison of their relative retention time and mass spectra with those of NBS75K library data of the GC-MS system. The mass spectra fragmentation pattern with a similarity index of more than 95 was used to confirm the type of compound.

\section{RESULTS}

\section{Antioxidant activities of the citronellal extract and fractions, and EOs of C. hystrix}

An antioxidant defined as a substance that can compete with other oxidizable substrates at low concentrations, preventing their oxidation. The DPPH radical-scavenging activities of the citronellal extract and fractions and EOs of parts of $C$. hystrix, citronella, and the standard (BHT) were tested. The $50 \%$ inhibition concentrations ( $\mathrm{IC}_{50}$ values) of each sample are presented in Figure 1.

\section{Chemical compounds of citronellal extract and fractions and EOs of $C$. hystrix}

The constituent chemical compounds of the EOs produced by steam distilled twigs, twigs-leaves and peels of $C$. hystrix, extracts of $C$. hystrix leaves oil and analyzed fractions produced by the fractional distillation of $C$. hystrix twigs oil were analyzed by GC-MS method. The chemical compositions (grouped in HMs and OMs) listed in Table 1, and the fractions produced by fractional distillation under reduced pressure and reflux ratio presented in Figure 2 and Figure 3 as HM and $\mathrm{OM}$ groups, respectively. Chemical composition of citronellal extract is presented in Figure 4.

The content of chemical compounds in CHT, $\mathrm{CHTL}$, and $\mathrm{CHL}$ of the $\mathrm{HM}$ group was much less than that of the OM group. Therefore, the HM: $\mathrm{OM}$ ratio is small in CHP, and the chemical content of the HM group is slightly higher than that of the OM group (ratio HM: OM value 1.15).

The initial fractions (F1-F4) of the fractionated distillation product of $\mathrm{CHT}$ contained $\mathrm{HM}$ group compounds, i.e., sabinene, ( $\beta$ )-pinene, ( $\beta$ )myrcene, limonene, ( $\beta$ )-ocimene, and ( $\alpha$ )terpinene (Fig. 2). In F1, the content of the sabinene compound exhibited the highest percent increase (from 5.91\% to 19.83\%). The three chemical components of the OM group distributed in $\mathrm{F} 1-\mathrm{F} 9$ were linalool, citronellal, and isopulegol (Figure 3).

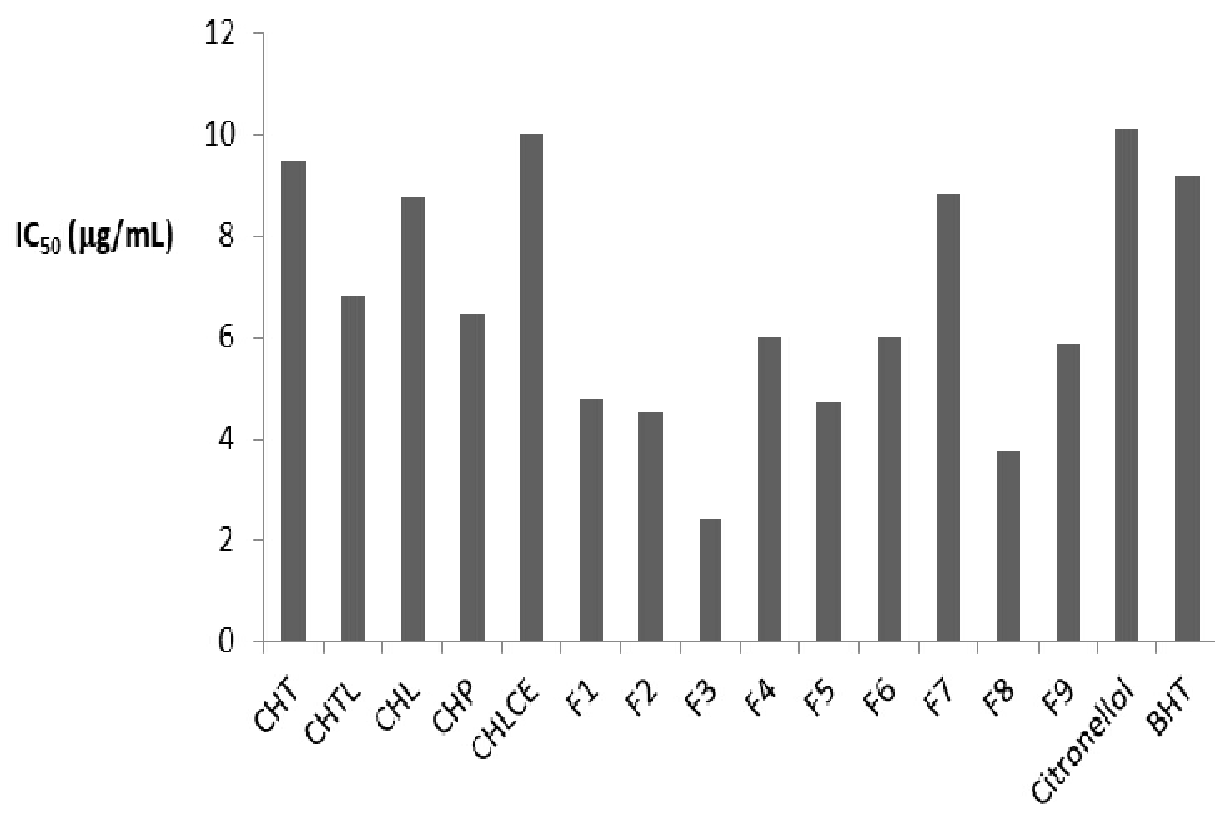

Figure 1: Antioxidant activity of each sample. $\mathrm{CHT}=$ C.hystrix twig oil, $\mathrm{CHTL}=C$. hystrix twigs-leaves oil, $\mathrm{CHL}=$ C. hystrix leaves oil, $\mathrm{CHP}=\mathrm{C}$. hystrix peel oil, $\mathrm{CHLCE}=$ citronellal extracted of $\mathrm{CHL}, \mathrm{F} 1$ to $\mathrm{F} 9=$ fractions were produced by $\mathrm{CHLT}$ fractional distillation, $\mathrm{BHT}=$ butylated hydroxytoluene 


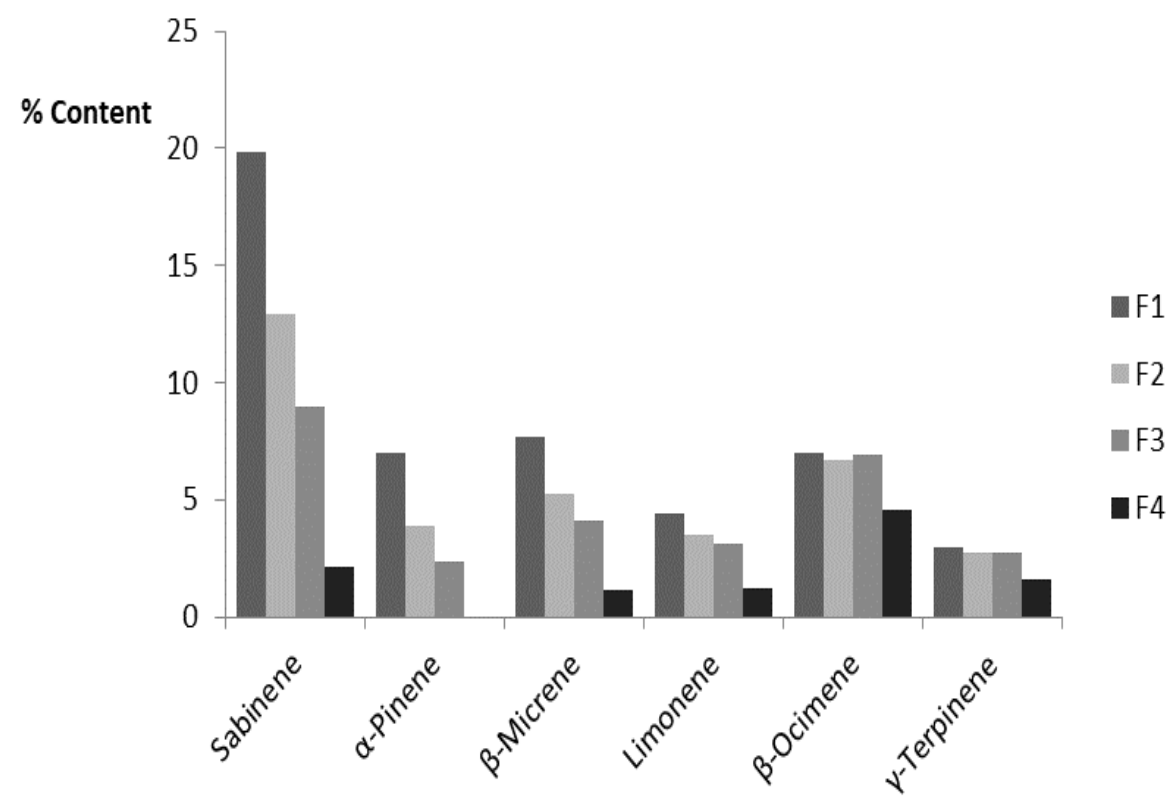

Figure 2: Composition of hydrocarbon monoterpene (HM) in F1 to F4 of CHT oil

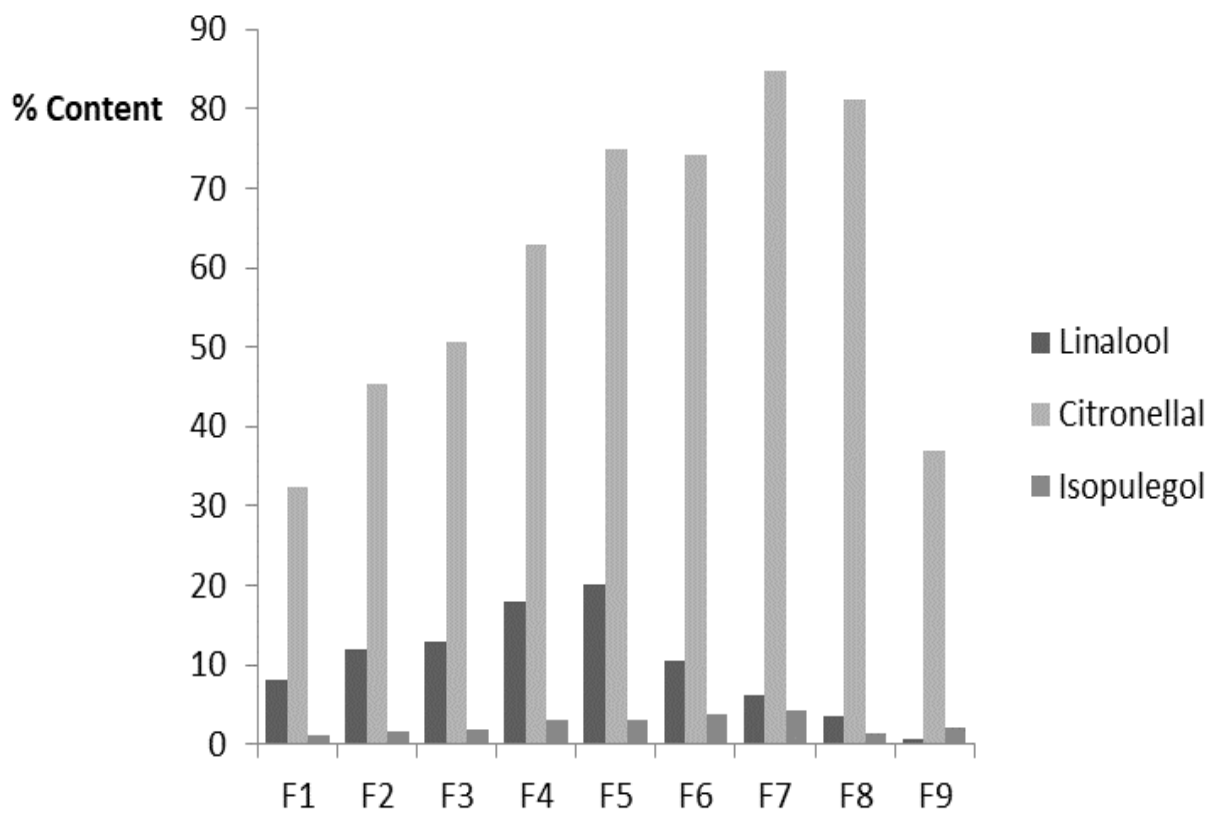

Figure 3: Composition of oxygenated monoterpenes in F1-F9 of $\mathrm{CHT}$ oil

Citronellal isolation performed by converting it into a salt using saturated $\mathrm{Na}_{2} \mathrm{SO}_{3}$ solution followed by hydrolysis in $\mathrm{Na}_{2} \mathrm{CO}_{3}$ solution, which increased the citronellal level from 81.52 to 88.58 $\%$.

\section{DISCUSSION}

In this study, the EO antioxidant activities of parts of C. hystrix, i.e., CHT, CHTL, CHL, and CHP, were evaluated by the DPPH radical scavenging assay and expressed as $I_{50}$ values. The same tests were also carried out for the fractions produced by fractionation distillation of $\mathrm{CHT}$. EOs with higher antioxidant activities exhibited lower $I_{50}$ values. The highest DPPH inhibition from the four types of $C$. hystrix oil was exerted by $\mathrm{CHP}$, with an $\mathrm{IC}_{50}$ value of $6.43 \mu \mathrm{L} / \mathrm{mL}$, followed by $\mathrm{CHTL}, \mathrm{CHT}$, and $\mathrm{CHL}$. Except for $\mathrm{F} 7$, the antioxidant activities of other fractions produced by fractional distillation of $\mathrm{CHT}$ were higher than the EOs of all parts of $C$. hystrix, with $\mathrm{IC}_{50}$ values ranging from 2.40 to $6.01 \mu \mathrm{g} / \mathrm{mL}$. This result suggests that $\mathrm{CHT}$ fractions exhibit a stronger 
Table 1: Constituent hydrocarbon and oxygenated monoterpene group of the EOs of $C$. hystrix

\begin{tabular}{|c|c|c|c|c|c|c|}
\hline \multirow[t]{2}{*}{ Groups } & \multirow[t]{2}{*}{ Compound } & \multirow{2}{*}{$\begin{array}{l}\text { Similarity } \\
\text { Index (SI) }\end{array}$} & \multicolumn{4}{|c|}{ Content (\%) } \\
\hline & & & CHT & CHTL & CHL & CHP \\
\hline Hydrocarbon & Phellandrene & 97 & - & - & - & 0.10 \\
\hline \multirow{15}{*}{$\begin{array}{c}\text { Monoterpene } \\
\text { (HM) }\end{array}$} & $(\alpha)$-Pinene & 97 & - & - & - & 1.26 \\
\hline & Sabinene & 96 & 5.91 & 3.57 & 2.79 & 9.21 \\
\hline & $(\beta)$-Pinene & 97 & 1.24 & 1.17 & 0.33 & 21.44 \\
\hline & ( $\beta$ )-Myrcene & 97 & 1.27 & 0.97 & 1.04 & 1.98 \\
\hline & Cymene & 97 & 0.80 & - & - & - \\
\hline & $(\gamma)$-Terpinene & 97 & - & - & - & 1.23 \\
\hline & Limonene & 95 & 0.90 & 0.26 & 0.13 & 12.59 \\
\hline & $(\beta)$-Ocimene & 97 & 1.56 & 0.77 & 0.44 & - \\
\hline & $(\alpha)$-Terpinene & 96 & 0.51 & 0.22 & - & 2.29 \\
\hline & $(\alpha)$-Terpinolene & 97 & - & - & - & 0.62 \\
\hline & Cyclo-germacrene & 96 & - & - & 0.3 & - \\
\hline & Copaene & 97 & - & - & - & 0.18 \\
\hline & Caryophyllene & 97 & 1.48 & 0.88 & 1.77 & 0.24 \\
\hline & Cadinene & 96 & - & - & 0.22 & 0.23 \\
\hline & Linalool oxide & 97 & - & - & 0.33 & 1.57 \\
\hline Oxygenated & Linalool & 97 & 13.11 & 6.1 & 3.46 & 4.23 \\
\hline \multirow{9}{*}{$\begin{array}{c}\text { Monoterpene } \\
\text { (OM) }\end{array}$} & Citronellal & 97 & 46.40 & 81.52 & 85.07 & 20.91 \\
\hline & Isopulegol & 95 & 1.57 & - & - & - \\
\hline & Terpinen-4-ol & 96 & 1.52 & 0.5 & & 11.93 \\
\hline & $(\alpha)$-Terpineol & 96 & 0.93 & - & - & 5.16 \\
\hline & Rhodinol & 95 & 0.59 & - & - & 0.46 \\
\hline & Citronellol & 98 & 11.03 & - & - & - \\
\hline & Citronellyl acetate & 96 & 6.76 & 3.65 & 2.77 & - \\
\hline & Geranyl acetate & 98 & 0.77 & 0.37 & 0.61 & 0.43 \\
\hline & Nerodinol & 95 & 1.11 & - & - & - \\
\hline Rasio HM/OM & & & & .09 & 08 & 15 \\
\hline
\end{tabular}

$\mathrm{CHT}: \bar{C}$. hystrix twigs oil, CHTL : $C$. hystrix twigs-leaves oil, $\mathrm{CHL}: C$. hystrix leaves oil, $\mathrm{CHP}: C$. hystrix peels oil

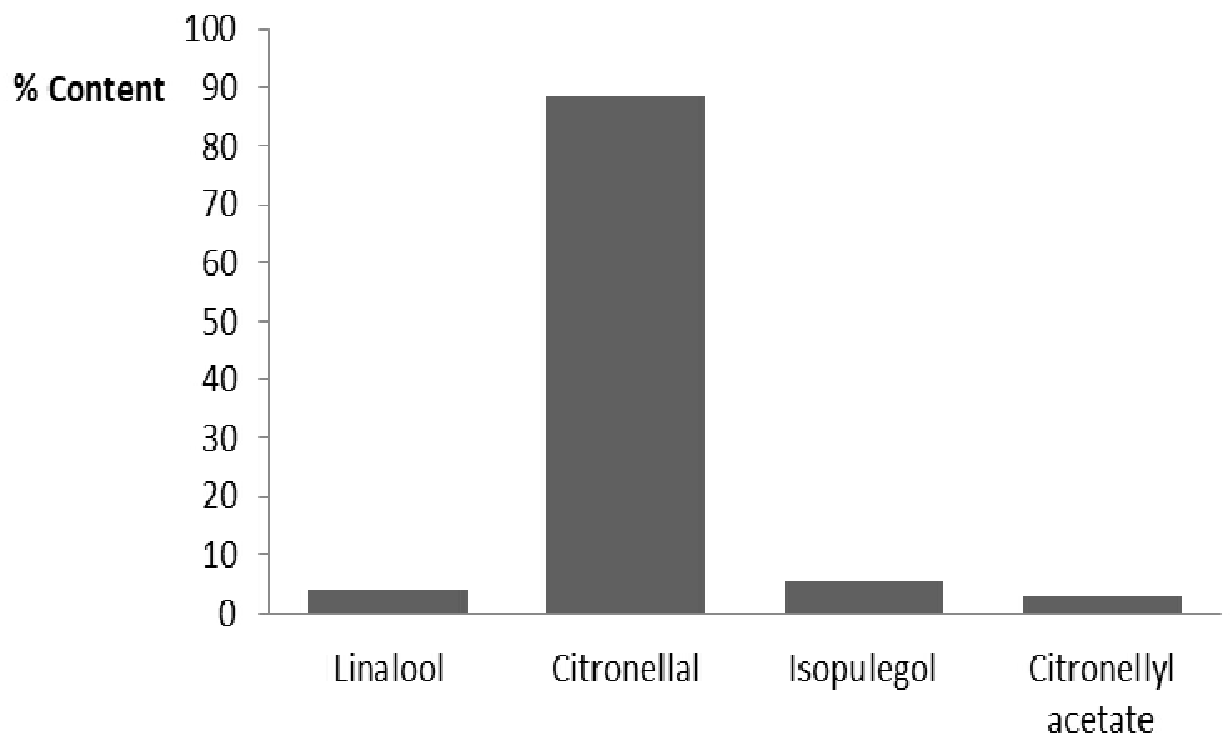

Figure 4: Composition of $\mathrm{OMs}$ in the citronellal extract of $\mathrm{CHL}$

inhibitory effect against $\mathrm{DPPH}$ radicals, as demonstrated by $\mathrm{F} 3$, with an $\mathrm{IC}_{50}$ value of 2.40 $\mu \mathrm{L} / \mathrm{mL}$.

The antioxidant activities of $\mathrm{CHT}, \mathrm{CHTL}$, and $\mathrm{CHL}$, as well as the $\mathrm{CHT}$ fractions (F1-F9), were stronger than those of citronellol and the BHT reference.

The difference in antioxidant activities of the EOs was due to the different chemical compounds containing $\mathrm{HM}$ and $\mathrm{OM}$ groups. A previous study reported that DPPH scavenging capacity was due to different HM groups, such as $\beta$-pinene, 
sabinene, and $\mathrm{Y}$-terpinene pomelo of the EOs of the peels $[9,10]$, and the phi $(\pi)$ bonds in the monoterpene compounds are responsible for the free radical-scavenging activity of DPPH $[11,12]$. These three components were higher in CHP than in $\mathrm{CHT}, \mathrm{CHTL}$, and $\mathrm{CHL}$. Furthermore, the terpene compounds (F1-F4) produced by fractional distillation, thus causing antioxidant activities that were higher than $\mathrm{CHT}, \mathrm{CHTL}$, and $\mathrm{CHL}$ (including $\mathrm{CHP}$ ).

Although HMs is an active compound to the free radical-scavenging activity of $\mathrm{DPPH}$, none are stronger than OMs. The antioxidant activities of EOs may attribute to the synergistic effects of their different major and minor components. EOs from Lavandula angustifolia (France) with a linalool compound content of $23.49 \%$ and $37.31 \%$ exhibit robust antioxidant activity [13]. Previous studies have shown that OM compounds, such as thymol, carvacrol, $\alpha$ terpineol [14], trans-citral, cis-citral, and geraniol [15], play an important role in antioxidant activity.

The results from the present study indicate that the antioxidant activities of F1-F9 (except F7) of $\mathrm{CHT}$ attributed to the combination of linalool and isopulegol compounds. The distribution patterns of these two compounds in the fractions increased from $\mathrm{F} 1$ to $\mathrm{F} 5$, with values ranging from $9.43 \%-23.21 \%$, and decreased in F6-F9, with values ranging from $13.98 \%-2.74 \%$. Citronellal acts as the primary component of citronellal extract) (Fig. 3), fractions of CHT (Fig. 2 ), and the EOs of part of $C$. hystrix (Table 1). However, their inhibitory effects against DPPH radicals were not related to the higher content of citronellal, including the citronellol compound.

\section{CONCLUSION}

The EOs of $\mathrm{CHP}$ and $\mathrm{F} 3$ produced from the EO fractional distillation of $\mathrm{CHT}$, with nearly equal composition of HMs and OMs, exhibited higher antioxidant activity than the other EOs and fractions.

\section{DECLARATIONS}

\section{Acknowledgement}

The authors thank Institute of Essential Oils of Brawijaya University for facilitating this research.

\section{Conflict of Interest}

No conflict of interest associated with this work.

\section{Contribution of Authors}

The authors declare that this work was done by the authors named in this article and all liabilities pertaining to claims relating to the content of this article will be borne by them.

\section{REFERENCES}

1. Bakkali F, Averbeck $S$, Averbeck D, Idaomar $M$. Biological effects of essential oils-a review. Food Chem Toxicol 2008; $46 \quad$ (2): $446-475$. Doi:10.1016/j.fct.2007.09.106

2. Bayala B, Bassole NHI, Scifo R, Gnoula C, Morel L, Lobaccaro AJ, Simpore J. Anticancer activity of essential oils and their chemical components - a review. Am J Cancer Res 2014; 4(6): 591-607. PMCID: PMC4266698.

3. Aswanida, NN. A Review on the Extraction Methods Use in Medicinal Plants, Principle, Strength and Limitation. Med Aromat Plants. 2015; (4)3: 1-6. doi.org/10.4172/2167-0412.1000196

4. Dhifi W, Bellili S, Jazi S, Bahloul, N, Mnif W. Essential oils' chemical characterization and investigation of some biological activities: A Critical Review. Medicines 2016; 3(25) : 1-16. doi:10.3390/medicines3040025

5. Saxena $M$, Saxena Jy, Nema $R$, Singh $D$, Gupta $A$. Phytochemistry of Medicinal Plants. J Pharmacogn Phytochem 2013, 1(6): 168-182.

6. Othman SNAMd, Hassan MA, Nahar L, Basar N, Jamil S, Sarker SD. Essential Oils from the Malaysian Citrus (Rutaceae) Medicinal Plants. Medicines 2016; 3(13): 211 doi:10.3390/ medicines3020013

7. Warsito $W$, Palungan $\mathrm{MH}$, Utomo EP. Profiling study of the major and minor components of kaffir lime oil (Citrus hystrix DC.) in the fractional distillation process. Pan Afr Medical J 2017; 27(282): 1-9.

8. Ratseewo J,Tangkhawanit E, Meeso N, Kaewseejan N, Siriamornpun $S$. Changes in antioxidant properties and volatile compounds of kaffir lime leaf as affected by cooking processes. 2016; Inter. Food Res. J.I 23(1): 188-196

9. Lan-Phi NT and Vy. TT. Chemical composition, antioxidant and antibacterial activities of peels' essential oils of different pomelo varieties in the south of Vietnam. Inter. Food Res. J. 2015; 22(6): 2426-2431

10. Andrade MA, Cardoso MG, de Andrade J, Silva LF, Teixeira ML, Resende JMV, da Silva Figueiredo $A C$, Barroso, JG. Chemical Composition and Antioxidant Activity of Essential Oils from Cinnamodendron dinisiiSchwacke and Siparuna guianensis Aublet. 2013; Antioxidants. 2, 384-397. ISSN 2076-3921. doi:10.3390/antiox2040384

11. Miguel MG. Antioxidant and anti-inflammatory activities of essential oils: A short review. Molecules 2010; 15: 92529287. Doi: 10.3390/molecules 15129252.

12. Wojtunik KA, Ciesla LM, Waksmundzka-Hajnos M. Model studies on the antioxidant activity of common terpenoid constituents of essential oils by means of the 2,2- 
diphenyl-1-picrylhydrazyl methods. J Agric Food Chem 2014; 62(37): 9088-9094. Doi: 10.1021/ff502857s.

13. Luís $A$, Duarte AP, Pereira $L$ and Domingues F. Chemical Profiling and Evaluation of Antioxidant and AntiMicrobial Properties of Selected Commercial Essential Oils: A Comparative Study. Medicines 2017; 4(36). doi:10.3390/medicines4020036

14. Bicas JL, Neri-Numa IA, Ruiz ALTG, De Carvalho JE, Pastore GM. Evaluation of the antioxidant and antiproliferative potential of bioflavors. Food Chem
Toxicol Int J Publ Br Ind Biol Res Assoc. 2011; 49: 1610-1615. doi:10.1016/j.fct.2011.04.012

15. Ancello F, Petretto GL, Zara S, Sanna ML, Addis R, Maldini M, Foddai M, Rourke JP, Chessa M, Pintore G. Chemical characterization, antioxidant capacity and antimicrobial activity against food related microorganisms of Citrus limon var. pompia leaf essential oil. LWT-Food Sci Technol. 2016; 69: 579585. 